\title{
Teenage childbearing in Great Britain and the spatial concentration of poverty households
}

\author{
A McCulloch
}

\begin{abstract}
Study objective-To investigate the association between the spatial concentration of deprived households and teenage nonmarital childbearing. Associations with area deprivation are tested before and after allowing for levels of personal deprivation.
\end{abstract}

Design and setting-The individual data are derived from the $2 \%$ sample of anonymised records (SAR) from the census of 1991 in Great Britain, and are combined with area data from the 278 districts of residence identifiable in the SAR.

Participants-Sample is restricted to unmarried women living at home (with at least one parent) and aged 16 to 19 .

Main results-The results suggest generally higher risk of teenage childbearing for women who are economically inactive, women from households with no access to a car or households resident in local authority accomodation. Without adjusting for personal circumstances, the risk of teenage pregnancy shows a clear, significant and approximately linear association with social deprivation of area of residence in 1991. Residual analysis shows that many urban areas have much higher levels of teenage childbearing than expected. When adjustment is made for personal disadvantage the simple association with local area deprivation is attenuated. A higher risk of teenage childbearing is still seen in urban areas while the areas having the highest negative differentials are heterogeneous.

Conclusions-Both individual and spatial characteristics are important in influencing levels of teenage childbearing. Teenage childbearing shows an association with residence in more deprived areas. The association seems to be largely because residence in more deprived areas is associated with personal disadvantage, which increases the risk of teenage childbearing. Area characteristics are of lesser significance in determining teenage nonmarital childbearing than individual and household characteristics.

(f Epidemiol Community Health 2001;55:16-23)

Institute of Social and Economic Research, University of Essex, Colchester CO4 3SQ, UK

Correspondence to: Mr McCulloch (amccul@essex.ac.uk)

Accepted for publication 22 August 2000 lands and ten times that of Switzerland. Another major theme in fertility behaviour in recent times is the dramatic rise in childbearing outside marriage. In the UK teenage mothers are the most likely of all mothers to be having a child on their own in the sense of not living with a partner. In 1994, only 39 per cent of teenage births were registered by a mother and father living at the same address, 33 per cent were registered by the mother alone and the remaining 27 per cent were registered by both parents who were living at different addresses at the time of the birth. Teenage childbearing is viewed as a social and economic problem because of the presumed adverse effects on the human capital and the future productivity of both teen unmarried mothers and their children. While the longer term impacts of early non-marital childbearing on young mothers is unsettled among researchers, ${ }^{1}$ the adverse effects of being born to a teen mother are not. There is substantial evidence that the children born to teenage mothers (especially those who are not married) are more likely to grow up in a poor and mother only family, live in a poor or underclass area, and experience high risks to both their health status and school achievements. $^{23}$

In July 1998 the current Government decided that the issues of teenage pregnancy and early parenthood should be examined by its Social Exclusion Unit. In a year long consultation process the Unit has examined both the reasons for the high UK teenage pregnancy rate and the consequences for those teenagers who actually become pregnant. The Unit's report has recently been published, ${ }^{4}$ with comprehensive recommendations for those working with young people, families or in sexual health services. In response to the report, the Government has allocated 60 million pounds to support its recommendations for local and national coordination, improvements in sex education and contraceptive services, and support for pregnant teenagers and teenage parents. The campaign aims to halve the rate of teenage pregnancy in the UK over the next 10 years.

This article explores the role of area characteristics in determining the probability of teenage non-marital childbearing. There is a growing body of research that examines the characteristics of areas that affect children, youth and families; the nature of those effects; and the mechanisms and mediating processes at the area, family and individual levels through which the effects operate. ${ }^{5}$ A number of recent observers have pointed to socioeconomic status as a feature of the area that may influence 
adolescents behaviours through its relation to both the opportunities for attainment that teenagers perceive as open to them, and to the normative patterns of behaviour that they observe in the adults around them. Wilson ${ }^{67}$ argued that the increasing concentrations of male joblessness, poverty and female headed households in American cities in the 1970s and 1980s may have led to social isolation and a shift in areas social and cultural norms. Wilson ${ }^{7}$ argues that the presence of disadvantaged neighbours encourages premarital childbearing and other non-normative or undesirable behaviours because high poverty areas lack "mainstream role models that help keep alive the perception that education is meaningful, that steady employment is a viable alternative to welfare and that family stability is the norm, not the exception (page 56)". According to this view, families who live in deprived areas may establish family routines that may be less conducive to the development of skills associated with school and work. Parents who feel that they lack personal control over their lives may lack daily planning or organisation skills that are conducive to success in school or employment. In contrast, families living in more affluent areas, where more parents have access to jobs, may reinforce family practices conducive to future success.

The evidence on the existence of effects of concentrated poverty upon non-marital childbearing is largely consistent across studies. Many $^{8-12}$ but not all ${ }^{13}$ studies report significant inverse effects of some dimension of area socioeconomic status on a young woman's risk of having a non-marital birth, net of the socioeconomic characteristics of her family of origin. Despite differences in the populations studied and in the operational definitions of area these studies together suggest that teenage women who reside in poorer areas are more likely to have a premarital birth than teenage women who reside in more affluent areas. In this article we present a formal test for the existence of the poverty concentration effects hypothesised by Wilson. ${ }^{6}$ Our analysis will first establish the existence of a gradient in the probability of non-marital teenage childbearing across deciles of an area deprivation score. The measured impact of family structure and material disadvantage, such as living in low status housing and lack of commodities such as a car, will then be assessed. If area environments contribute to differences in the probability of teenage childbearing then the controls for area context should be significant predictors of teenage childbearing alone and with controls for the individual's own attributes and family background.

The risk for a teenage woman to have a nonmarital birth varies by characteristics of the woman's family of origin, the woman's own demographic and socioeconomic attributes and features of her place of residence. Both parental economic resources and family structure have been shown to be important determinants of non-marital childbearing. Parental economic resources reduce the risk of a non-marital birth perhaps because they allow young women to pursue roles that conflict with early sexual activity and childbearing. ${ }^{14}$ Growing up in a single parent family substantially raises the risk of a teenage non-marital birth partly because of the lower and unstable incomes of single parent families. The risk of a non-marital birth varies by young women's own demographic and economic characteristics. Non-marital fertility rates increase from the teenage years to the early 20 s and declines thereafter. Being in education or having a job also seems to reduce the risk of a non-marital birth. Recent analyses using the ONS Longitudinal Study shows that girls living in local authority rented accomodation were over three times more likely to become a teenage mother compared with girls living in owner occupied accomodation. ${ }^{15}$ Studies have shown that teenage conceptions are several times as likely in the most deprived areas as in the more affluent areas. Teenage lone mothers who head their own household are more likely to live in areas of social housing (that is, rented from a local authority or housing association) than the population as a whole. From the 1991 Census, lone teenage mothers were six times more likely than the general population to live in areas where more than 75 per cent of the housing was social housing. Almost one in four lone teenage mothers who are head of their household live in local authority areas with more than 50 per cent social housing, compared with only 8 per cent of heads of household in England as a whole.

\section{Methods}

For the first time in a British census, the 1991 statistical output included Samples of Anonymised Records (SARs). ${ }^{16}$ Known as Census Microdata or Public Use Samples in other countries, SARs differ from traditional census output of tables of aggregated information in that abstracts of individual records are released. The individual SAR is a $2 \%$ sample of individuals (1.1 million in total) resident in households and communal establishments. The level of geographical detail in the individual $2 \%$ SAR was chosen such that an area had to have a population size of at least 120000 to be separately identifiable. Thus the $2 \%$ SAR identifies 278 areas in Great Britain that are based on aggregation of the 459 local authority districts. The SARs contain the full range of census variables. The $2 \%$ SAR also contains limited information about the sex, economic position and social class of the individual's family head and a few summary variables about other members of the individual's household, such as the number of persons with long term illness and the number of pensioners. The geography of the $2 \%$ SAR provides a unique opportunity to model area level effects in analyses that hitherto were usually confined to individual or household characteristics or, at best, regional effects. As there is no information on the ward of residence in the SAR dataset, the best approximation to ecological data comes from the census data on these SAR districts. As SAR districts are quite large, they may well be suited 
as units to study contextual effects operating over fairly wide areas. SAR areas are large enough to allow the feasible investigation of the effects of social and economic resources such as employment opportunities. However, they are internally heterogeneous and they provide rather general information on geographical context with less local precision than data for smaller areas.

In this paper the analyses are restricted to unmarried women living at home (with at least one parent) and aged 16 to 19 . Although marital status (MSTATUS), family type (FAMTYPE) and the relationship to the household head (RELAT) are provided in the SAR, these variables do not allow us to distinguish families where the adult parent is a lone mother and families where the teenage woman is a lone mother. Fortunately, a derived variable (GENIND) has been added to the SAR and this allows different generations within the household to be distinguished. Our sample contains 22510 respondents of whom 398 were recorded as forming the second generation living in a lone parent family with one or more dependent children. There may be some 16-19 year old single mothers who we are unable to identify from the census records. For example, in a four generational household the head of household could be an elderly person living with son/daughter who, in turn, were living with their unmarried daughter and child. Such cases are probably very rare.

Several recent papers analysing area and peer effects on behaviour have highlighted the difficulty of controlling adequately for family characteristics and choice in identifying area and peer influence. By focusing on teenage childbearing we can presume that the residential choice is made by the parent. In addition census data include extensive data on the household in which people reside, permitting us to control for a variety of family characteristics. These include indicators of deprivation: housing tenure, car access, the number of earners in the household and room density (greater than one person per room). As an indicator of maternal resources we include the teenage mother's current labour force status. The 278 SAR areas are grouped into 12 regions of Great Britain. Previous work indicates that there are broad regional differences in outcomes not accounted for by individual or local characteristics and these regional contrasts were also estimated in the fixed part of the model. This also helps to control for the endogeneity of residential location. Despite this, there may still be other omitted family characteristics that are simultaneously correlated with location and youth behaviour and for which this study cannot control accurately.

We would probably expect that moving home and teenage childbearing are intimately linked. Therefore, the rate of teenage childbearing among the sample of individuals that do not move home is likely to differ from the rate in the entire population. It is difficult to predict the direction in which this selection process might bias estimates of area influences. However, individuals and households particu- larly ill equipped to cope with areas of concentrated poverty probably are most likely to live in them because they do not have the (partly unmeasured) resources to move to more advantaged areas. In this case, the coincidence of an area of high poverty and teenage childbearing results from both the lack of the resources needed to move home and the high incidence of characteristics associated with teenage childbearing, thus resulting in an overestimation of current area conditions' effects.

An important measurement issue in research on community and area influences is whether to use measures of single area characteristics or construct multivariate indices of underlying dimensions of area organisation. Area deprivation was assessed by the Townsend index of four components; each measured for the area of residence at the 1991 census. ${ }^{17}$ These components were: the proportion of the labour force unemployed, the proportion of households with no car access, the proportion of households with one person per room and over and the proportion of households not owning their own home. The 1991 census indicated that a substantial proportion of the population still lived in rented properties $32 \%$ in the UK and $48 \%$ in Scotland) or had no car access ( $43 \%$ in the UK and $47 \%$ in Scotland). The indicators for levels of unemployment and overcrowding were logged, and the index was standardised into $\mathrm{Z}$ scores. For the purpose of analysis the score was categorised into 10 decile groups at a national level. Notwithstanding the debate about the various merits and demerits of these scores, they have the advantage of simplicity in allowing areas to be ranked against each other for statistical comparisons.

In the analysis of the impact of individual and area characteristics on teenage childbearing, the response variable for woman $i$ in area $j$, $\mathrm{Y}_{\mathrm{ij}}$, is a discrete variable indicating whether the woman has had a non-marital birth. A common choice for the analysis of discrete data is the logistic regression model. The usual fixed effects logistic model is written as:

$\pi_{i j}=\frac{\exp \left(\eta_{i j}\right)}{1+\exp \left(\eta_{i j}\right)}$

with:

$\eta_{i j}=X_{i j} \beta$

where $\pi_{\mathrm{ij}}=$ probability of a positive outcome, $\mathrm{x}_{\mathrm{ij}}$ $=$ vector of covariates, and $\beta=$ vector of parameters associated with $x_{i j}$. This formulation assumes that all of the variation in the individual probabilities $\pi_{\mathrm{ij}}$ can be explained by the covariates. The random effects logistic model extends this model by assuming that the individual probability of a positive outcome equals the fixed effects, as above, plus a random perturbation on the logit scale because of an unobserved area effect. ${ }^{18}$ This model is written as

$\eta_{i j}=X_{i j} \beta+\kappa_{j}$ 
Table 1 Distribution of teenage non-marital childbearing by $S A R$ area

\begin{tabular}{lrrrrrrr}
$* \begin{array}{l}\text { *umber of } \\
\text { women per } \\
\text { SAR area }\end{array}$ & \multicolumn{7}{c}{ Number of births per SAR area } \\
\cline { 2 - 8 } & 1 & 2 & 3 & 4 & 5 & $6-10$ \\
\hline $23-60$ & 32 & 27 & 8 & 2 & 1 & 0 & 0 \\
$61-75$ & 32 & 24 & 12 & 6 & 0 & 0 & 0 \\
$76-92$ & 21 & 17 & 16 & 9 & 1 & 0 & 2 \\
$93-382$ & 10 & 15 & 12 & 9 & 7 & 8 & 7 \\
Total & 95 & 83 & 48 & 26 & 9 & 8 & 9 \\
\% Areas & 34 & 30 & 17 & 9 & 3 & 4 & 4 \\
$\%$ Births & 0 & 21 & 24 & 20 & 9 & 10 & 16
\end{tabular}

^Unmarried women living at home (with at least one parent) and aged 16 to 19 .

where the $\kappa$ represent area specific differences in the log odds of a positive outcome. They summarise the degree to which the area specific probabilities differ from their average population values. The unobserved value of $\kappa$ associated with a particular community is assumed to come from a distribution with mean zero. Hence $x_{i j} \beta$ is the mean $\operatorname{logit}\left(\pi_{\mathrm{ij}}\right)$ across areas associated with a particular set of characteristics. The $\operatorname{logit}\left(\pi_{\mathrm{ij}}\right)$ for an individual with a particular set of characteristics is this mean $\operatorname{logit}\left(\pi_{\mathrm{ij}}\right)$ plus a bit more if they come from a high risk area, or minus a bit if they come from a low risk area. Stated less formally: the unexplained area effects are governed by mechanisms that are roughly similar from one area to the next, and operate independently between the areas. The areas are said to be exchangeable. This assumption helps to counteract the paucity of the data that is implied by the relatively small sample sizes. As all area effects are assumed to come from the same population, the data from each area also have a bearing on inference with respect to the other areas, namely, through the information it provides about the population of areas.

In the logistic-normal model it is assumed that $\kappa$ has a $\mathrm{N}\left(0, \sigma^{2}\right)$ normal distribution. This seems intuitively sensible and can be supported with arguments from statistical theory. Often $\kappa$ is standardised producing the model in the form:

$\eta_{i j}=X_{i j} \beta+\sigma v_{j}$

where $v_{j}$ has a $\mathrm{N}(0,1)$ standard normal distribution and $\sigma$ is a scale parameter that indicates the variation across area on the logit scale and is the standard deviation of the normal distribution of $\kappa$. If $\sigma=0$, there is no variation across areas and hence no effect of the area; in such cases the model reduces to the ordinary logistic model. Hence it is possible to test the significance of area effects by testing the null hypothesis $\sigma=0$ against the alternative hypothesis $\sigma>0$. This can be done by using a modified likelihood ratio test based on the usual likelihood test statistic. In this case the test statistic is minus twice the difference between the log likelihood of the logistic model and the log likelihood of the corresponding logistic-normal model. The test must be modified to allow for the fact that it is testing on the boundary of the parameter space, so a one tailed normal test is used rather than the usual $\chi_{1}^{2}$ test. The estimated value of $\sigma$ can be interpreted as an ordinary regression coefficient representing the extent to which the standardised random area effect influences the outcome variable. The remaining parameters can be

Table 2 Results of regression models

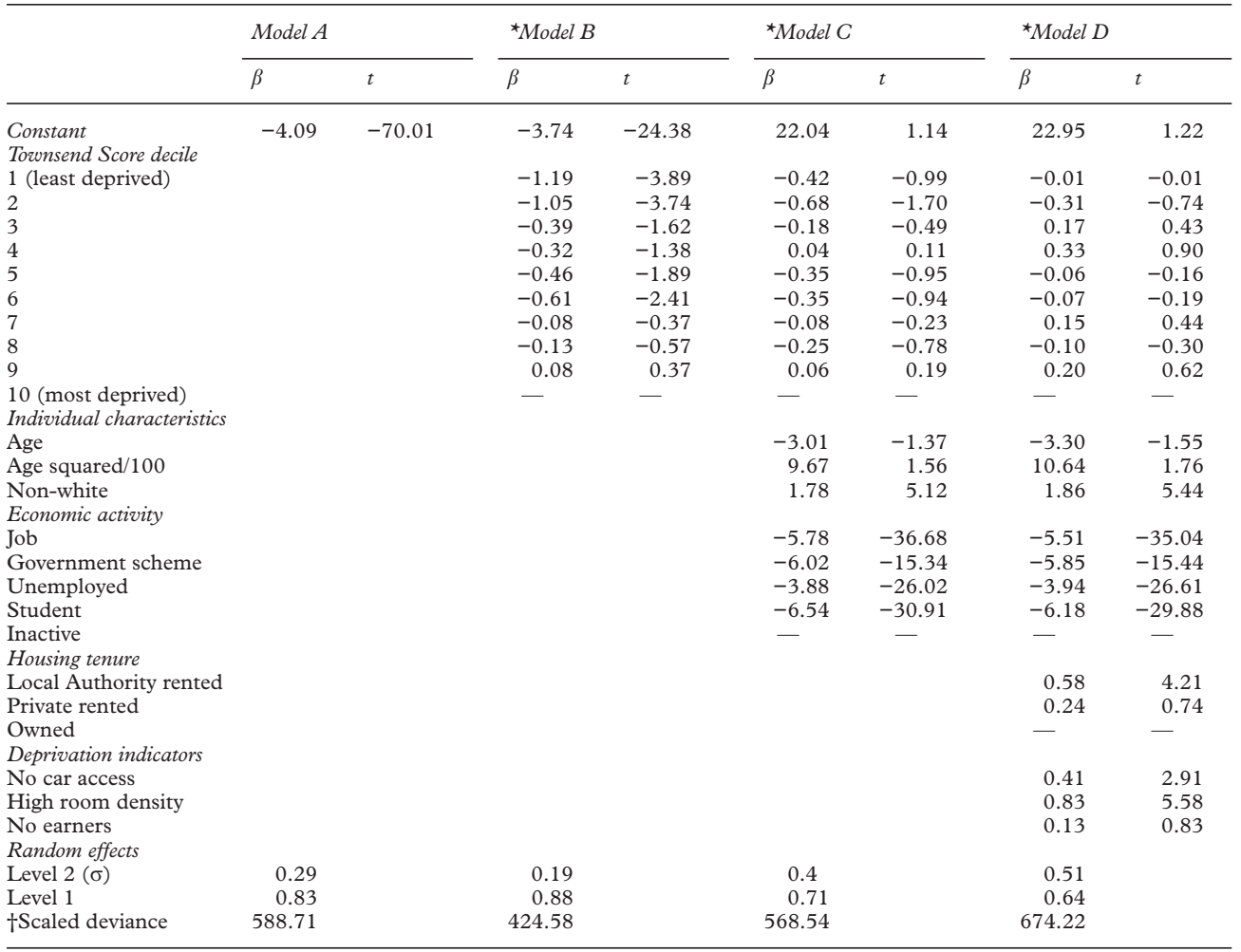

*Includes controls for region. †Difference in scaled deviance between random effects and ordinary logistic models. 


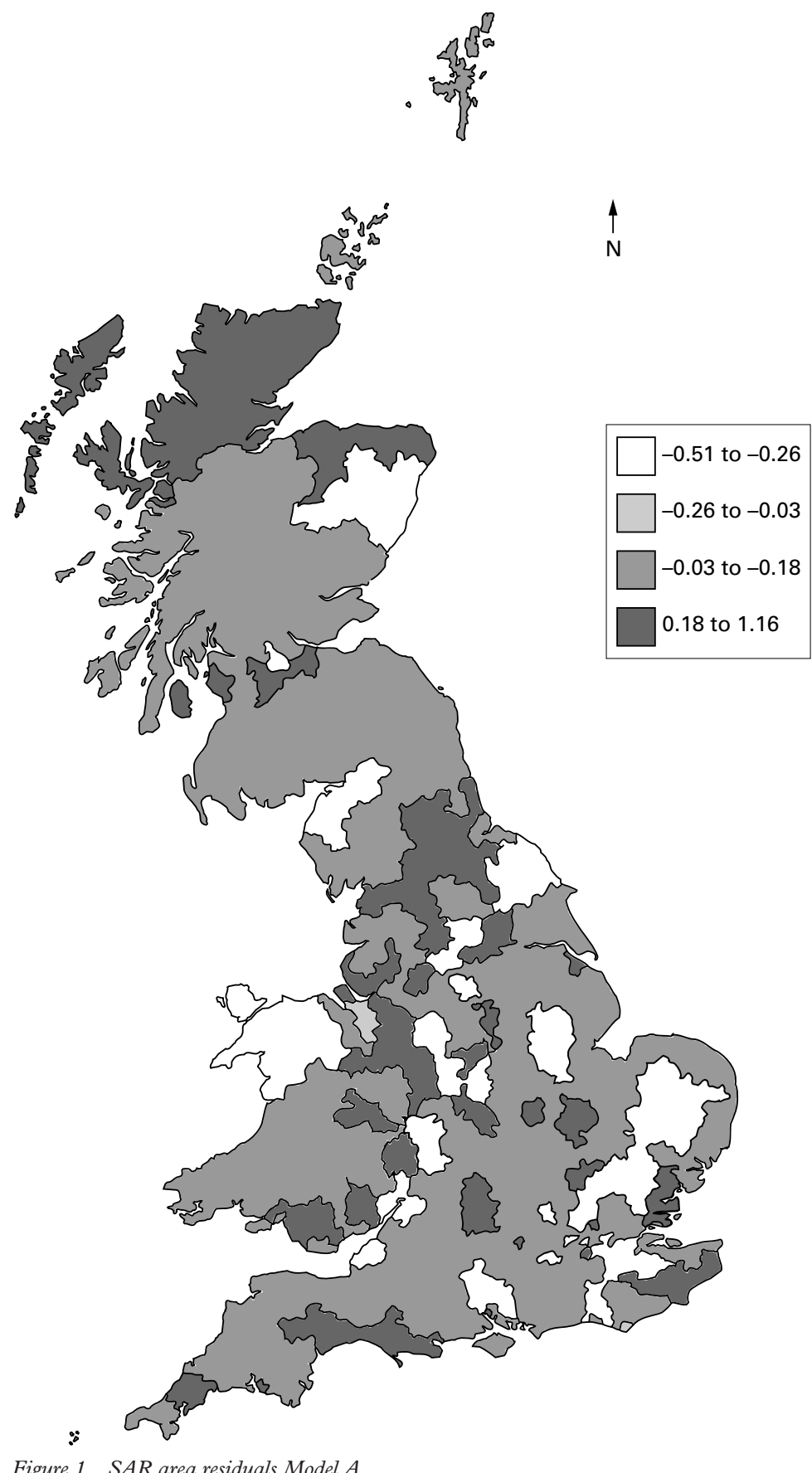

Figure 1 SAR area residuals Model A.

tested in exactly the same way as for logistic regression. An important feature of multilevel modelling for data such as these is the ability to calculate residuals at different levels of aggregation. These allow areas with markedly higher or lower rates of teenage childbearing than would be expected to be identified. An examination of the characteristics of such areas may identify further factors that are appropriate for inclusion in the statistical model.

\section{Results}

Table 1 shows the distribution of pre-marital teenage childbearing by SAR area. The number of women per area in the sample ranges from 23 to 382 . The proportion of women who have had a premarital birth increases with the size of the area. The mean number of women per area is 81 , and the mean number of births per area is 1.4. Slightly more than one third of the areas contained no cases of teenage premarital childbearing; the approximately 10 per cent of areas that contribute four or more cases together account for 35 per cent of all cases. Clustering of teenage premarital childbearing by area thus seems to be of some importance.

Table 2 presents a summary of the models described above. The multilevel structure applied here is dictated by the geographical units for which data are available. Being based on local authority boundaries, it is arbitrary, but nevertheless represents a useful framework for analysis. A two level structure of individuals (level 1) nested within SAR areas (level 2) was adopted. In Model A the only fixed term in the Model represents the log-odds of teenage nonmarital childbearing in the national sample. The estimated logit indicates that the probability of teenage non-marital childbearing is 0.016 . The level-1 term for the binomial variance is well below 1 , which is common where the multilevel data structure is sparse with few cases per area. ${ }^{19}$ Examining the level-2 random term of Model A suggests that there are notable differences between areas. The difference in the log likelihood between the multilevel logistic model and a single level logistic model shows that the area level random terms are significantly different from zero. That is to say, there is substantial variation between areas in the log-odds of teenage childbearing.

Model B adds the Townsend deprivation score to the model. Teenage childbearing shows a clear, significant and approximately linear association with social deprivation of area of residence in 1991. The results indicate the expected higher odds of teenage childbearing in the more deprived areas relative to the more affluent areas. Model C adds controls for region, ethnicity and current labour force status. Not surprisingly, women who are economically active have a lower odds of teenage childbearing than women who are inactive.

Family characteristics are also important in determining teenage childbearing (Model D). The reported log-odds indicate a higher risk of teenage childbearing in the more deprived households. Women from households with no access to a car or households resident in social housing have higher rates of non-marital childbearing than women with more family resources. In Model D the parameters of the area deprivation score are statistically insignificant and substantially attenuated in comparison to Model C. The results clearly demonstrate that indicators of personal deprivation rather than area deprivation dominate the explanation of teenage childbearing. The association of area deprivation and teenage childbearing seems to be largely because residence in more deprived areas is associated with personal disadvantage, which is a more significant determinant of teenage childbearing than area of residence.

The level-2 random term $(\sigma)$ provides an indication of the importance of the clustering 


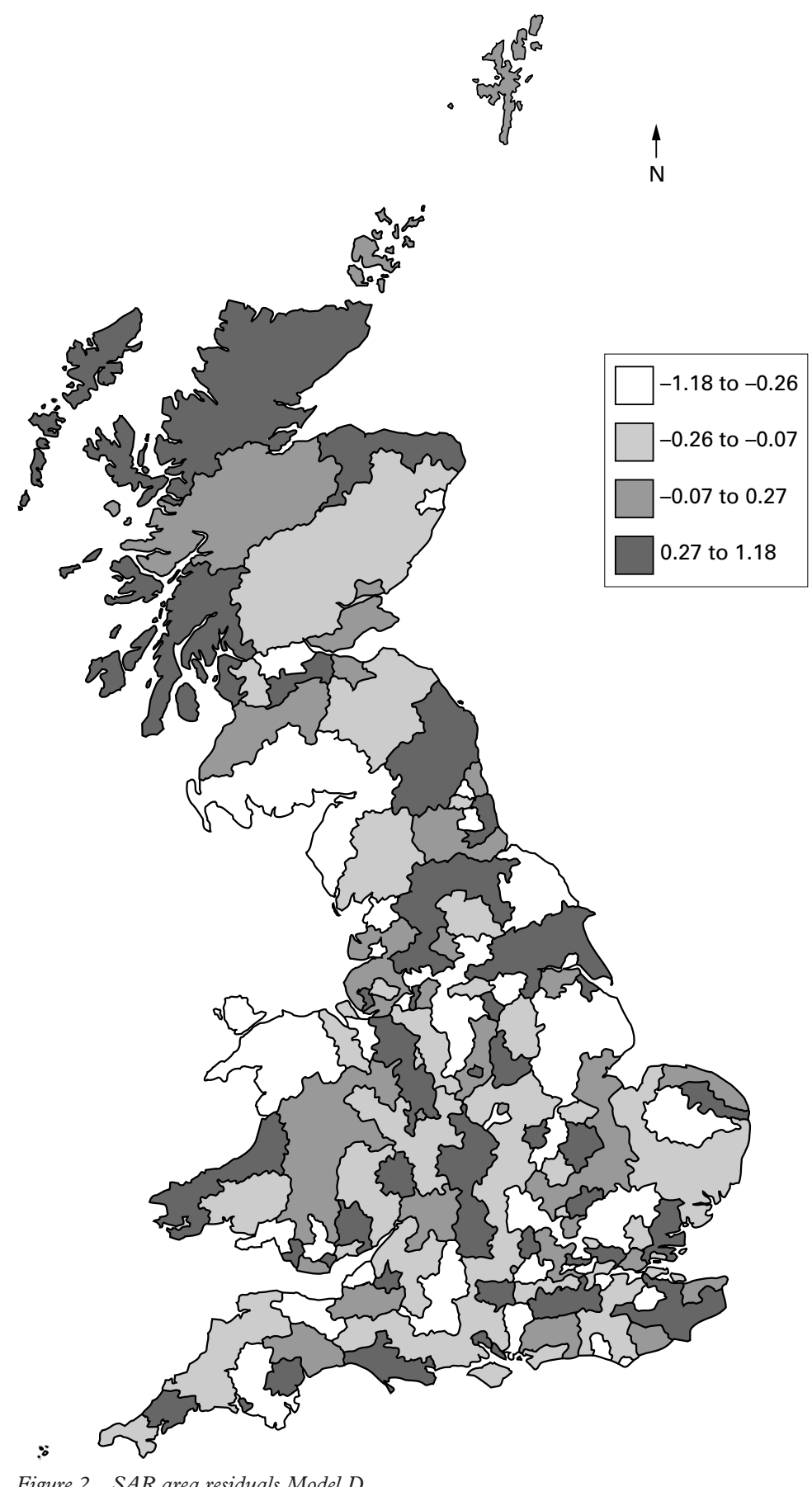

Figure 2 SAR area residuals Model D.

of childbearing within SAR areas after controlling for observed covariates. Controlling for individual characteristics and household circumstances does seem to increase the degree of heterogeneity between areas in terms of the log-odds of teenage pregnancy. The degree of random variation at the area level is much larger and statistically significant when controls for family and individual characteristics are added to the model. This could be interpreted to be a consequence of the multilevel data structure, which as we noted earlier is sparse with relatively few individual cases per cluster and a considerable proportion of the areas containing no positive responses. The unobserved ward characteris- tics $(\sigma)$ are statistically significant in all analyses as shown by the difference in scaled deviance between the random effects and ordinary logistic models. This could be interpreted to indicate the influence of further variables measured at the area level or that important variables measured at the individual level have been omitted from the statistical model.

A particularly useful aspect of multilevel models is the ability to identify area level (level 2 in this study) intercepts that, in our case, reflect the relative probabilities of teenage childbearing in each area, after controlling for a range of observable individual, household and area characteristics. Figures 1 and 2 map these estimates for Models A and D respectively, classifying the 278 SAR areas into four groups with approximately equal numbers of SAR areas in each. The estimated differential for the areas with the highest probabilities and the areas with the lowest probabilities of teenage non-marital childbearing are given in table 3. The estimated percentage of teenage women having a non-marital birth varies from a high of 5 per cent in Sunderland to a low of 1 per cent in Bromley. There are large apparent differences between areas. The general pattern is a direct association between teenage childbearing and deprivation. There is a marked contrast between declining industrial and metropolitan areas on one hand, and rural and suburban regions on the other. In figure 1 the dark shading indicates areas where the probabilities of teenage pregnancy are highest and many of these SAR areas are typical of areas of industrial decline or more metropolitan centres. Thus Liverpool, Manchester, Tyneside and Glasgow have much higher levels of teenage parenthood than expected.

In figure 2 areas where the probabilities of teenage childbearing are highest still include metropolitan areas such as Liverpool and Manchester. The differentials show complex changes (table 3B). While some effects are reduced, others show little change, while others show an increase. Marked positive differentials reflecting a higher risk of teenage non-marital childbearing are still seen in urban areas while the areas having the highest negative differentials are heterogeneous. What previously appeared to be differences based on geographical location are seen to be based to a considerable extent on geographical regions containing different types of places.

\section{Discussion}

We have explored the effects of areas on patterns of family formation by examining the impact of an index of area socioeconomic disadvantage on non-marital teenage childbearing controlling for several individual and family level indicators of socioeconomic status. As implied by Wilson's concept of concentration effects, we observe a significant relation between area disadvantage and non-marital fertility, with increasing rates of non-marital teenage childbearing occurring in especially disadvantaged communities. However, the associations of teenage non-marital childbearing 
Table $3 A$ Differentials for geographical regions (Model A)

\begin{tabular}{|c|c|c|c|c|c|}
\hline SAR area & Rank & Logit $\kappa_{j}$ & $S A R$ area & Rank & Logit $\kappa_{j}$ \\
\hline \multicolumn{3}{|l|}{ Negative differentials } & \multicolumn{3}{|l|}{ Positive differentials } \\
\hline Bromley & 1 & -0.50 & Caithness etc & 264 & 0.54 \\
\hline Leeds & 2 & -0.43 & Liverpool & 265 & 0.57 \\
\hline Sheffield & 3 & -0.42 & Coventry & 266 & 0.58 \\
\hline Croydon & 4 & -0.42 & Oldham & 267 & 0.59 \\
\hline Brcklnd S Nrflk & 5 & -0.40 & Plymouth & 268 & 0.63 \\
\hline Brxbourn E Herts & 6 & -0.39 & Easingtn.Sedgefd & 269 & 0.64 \\
\hline Barnet & 7 & -0.39 & Oxfd.Vofwh. Woxon & 270 & 0.67 \\
\hline Brent & 8 & -0.38 & Tameside & 271 & 0.69 \\
\hline Kirklees & 9 & -0.38 & Congle.Crewe. $\mathrm{Vr}$ & 272 & 0.73 \\
\hline Enfield & 10 & -0.38 & Walsall & 273 & 0.75 \\
\hline Sevoaks. Tonb\&Mal & 11 & -0.38 & Blackburn & 274 & 0.77 \\
\hline Alldale.Carlisle & 12 & -0.38 & Manchester & 275 & 0.89 \\
\hline Braintree.Uttfrd & 13 & -0.37 & Knowsley & 276 & 0.94 \\
\hline Forhth.Msflk.Ste & 14 & -0.37 & Nwctle/Lyme.Staf & 277 & 0.96 \\
\hline EStaff.Staffmoor & 15 & -0.36 & Sunderland & 278 & 1.15 \\
\hline \multicolumn{6}{|c|}{ Table $3 B \quad$ Differentials for geographical regions (Model D) } \\
\hline$S A R$ area & Rank & Logit $\kappa_{j}$ & $S A R$ area & Rank & Logit $\kappa_{j}$ \\
\hline \multicolumn{3}{|l|}{ Negative differentials } & \multicolumn{3}{|l|}{ Positive differentials } \\
\hline Sheffield & 1 & -1.18 & Redbridge & 264 & 0.63 \\
\hline Southwark & 2 & -1.01 & Burnley.Pendle & 265 & 0.65 \\
\hline Rochdale & 3 & -0.97 & Haringey & 266 & 0.69 \\
\hline Brcklnd.S Nrflk & 4 & -0.78 & Poole & 267 & 0.71 \\
\hline Hounslow & 5 & -0.76 & Cardiff & 268 & 0.75 \\
\hline Brent & 6 & -0.74 & Nottingham & 269 & 0.76 \\
\hline Dacorum & 7 & -0.73 & Ogwr & 270 & 0.77 \\
\hline Cumbernauld etc & 8 & -0.73 & Colchester & 271 & 0.77 \\
\hline Kirklees & 9 & -0.67 & Nwar.Nun\&Bed.Rug & 272 & 0.82 \\
\hline Leeds & 10 & -0.64 & Huntingdonshire & 273 & 0.84 \\
\hline Mertyd.Rhyv.Taff & 11 & -0.63 & Walsall & 274 & 0.91 \\
\hline Brntwd.Epfor.Har & 12 & -0.61 & Crv.Hmbtn.Richsh & 275 & 0.99 \\
\hline Aberdeen City & 13 & -0.61 & Oxfd.Vofwh.Woxon & 276 & 1.10 \\
\hline Langbaurgh/Tees & 14 & -0.59 & Purb.W Dors.Wy\&P & 277 & 1.11 \\
\hline E Hams.Havant & 15 & -0.56 & C/Point.Mald.Rfd & 278 & 1.18 \\
\hline
\end{tabular}

with a census based indicator of area deprivation are largely, if not entirely, accounted for by the individual measures of the indicators contributing to the deprivation score. This has led us to conclude that association of teenage childbearing and disadvantaged areas is primarily an association among individuals. It also suggests that if there are area effects over and above individual level relations they are not well identified by indices of area disadvantage.

The results suggest the importance of economic resources in shaping young women's evaluations of the benefits and potential costs of sexual activity. Young women show a greater propensity to engage in sexual activity when the potential consequences of such activityindexed by the economic characteristics of the local area and labour market experiences and economic resources - seem to be relatively low. The core reason why non-marital teenage childbearing in some areas is much higher than the national average however is that these areas contain relatively high proportions of households with characteristics that are associated with the experience of teenage childbearing.

Despite the growing body of evidence that area conditions play a part in shaping individual outcomes, serious methodological challenges remain that suggest some caution in interpreting this evidence. It may be difficult to identify and measure the area conditions that actually play the most important part in shaping outcomes. Many different factors or combinations of factors may influence individuals' outcomes and areas may differ widely in the factors that account for their resident's experiences. A second complication arises because it is difficult to separate the effects of area environment from the individual or household characteristics. Thus if studies of area effects fail to adequately control for the influence of individual and household characteristics, they may attribute to areas what are really the effects of the omitted household and individual variables. Some relevant individual characteristics are harder to observe however, and are generally not captured in empirical research.

Perhaps the most pressing need in future research on area effects is to identify the mechanisms through which area disadvantage (and other area characteristics) influence individual outcomes, including family formation events but also including other social behaviours, such as criminal activity. Peer group norms, ${ }^{1020}$ the absence of successful role models, ${ }^{9}$ access to community-based social capital, ${ }^{21}$ real and perceived opportunity costs, ${ }^{8}$ and both personal efficacy ${ }^{67}$ and collective efficacy $^{22}$ might all play important parts. Studies of the individual and community level mechanisms that mediate the effects of area characteristics on these and other outcomes will help refine theories of area effects, and more generally, increase our understanding of how social context influences social behaviour.

The multilevel analysis shows that contextual effects between areas do exist. There are areas where teenage non-marital childbearing tends to be clustered and this is not fully explained by the level of social deprivation in the area. This could be interpreted to indicate the influence of further variables measured at the area level or that important variables measured at the individual level have been omitted from the statistical model. Place of residence is likely to be a proxy for physical features of the environment, features of the domestic and working environment and for inequalities in the provision of and/or use of services. ${ }^{23}$ Where contextual effects exist they are probably location specific and are unlikely to be easily identified by routine use of aggregate census indicators. However, even if one knows that area effects both exist and are significant, it is not at all obvious how one should go about designing and implementing effective policy responses. For instance, it is not clear whether policies should be aimed at improving areas, helping people move out of poor areas, or improving the job markets in urban areas.

Whether and by what means the characteristics of areas influence individual outcomes are questions not only of theoretical interest to social scientists but also of immense importance to policy makers tackling social inequality. The results in this paper indicate that measurable characteristics of the areas add little to our ability to explain variation in rates on non-marital teenage childbearing, once we included a full range of individual and family level variables. The policy implications of our results are clear. One would be more inclined to move slowly on area level interventions wherever one could as easily (as efficiently, and with no greater cost) implement macroeconomic, family level or individual level interventions. Thus one would be inclined to emphasise 
KEY POINTS

- The role of area deprivation in the explanation of teenage premarital childbearing is secondary. The role of personal characteristics is overriding.

- The results support an emphasis on the role of individual and household material conditions for variations in teenage premarital childbearing.

- Multilevel analysis shows that there are areas where teenage premarital childbearing tends to be clustered and that this is not fully explained by the level of social deprivation in the area.

- Areas with high estimated rates of teenage premarital childbearing include metropolitan and urban areas such as Liverpool and Manchester.

the importance of macroeconomic policies that influence the resources and longer term opportunities available to families. Government policy (and expenditure) on education, employment, housing, social security and families will have by far the greatest impact on the economic circumstances and life chances of those living in the poorest areas. The arguments against area-based interventions do not imply that there is no place for intervention of any kind. Interventions that are directly targeted at individuals with specific problems can work. But the most effective way of tackling those inequalities that arise from individual poverty is to tackle poverty itself.

Thanks are due to Professor A Dale for advice on using the SARs.

Funding: this study was funded by the Economic and Social Research Council as part of their Cities Programme. Grant number L130251010.

Conflicts of interest: none.
1 Shouls S, Whitehead M, Burstrom B, et al. The health and socioeconomic circumstances of British lone mothers over the last two decades. Popul Trends 1999;95:41-6.

2 Kiernan K. Lone motherhood, employment and outcomes for children. International fournal of Law, Policy and the Family 1996;10:233-49.

3 Kiernan, K. Teenage motherhood-associated factors and consequences - the experiences of a British birth cohort. $\mathcal{F}$ Biosoc Sci 1980;12:393-405.

4 Report on Teenage Pregnancy. Social Exclusion Unit report to the Prime Minister. London: HMSO, 1999.

5 Brooks-Gunn J, Duncan G, Aber JL, eds. Area poverty: context and consequences for development. New York: Russell text and consequences for
Sage Foundation, 1997.

6 Wilson WJ. The truly disadvantaged: the inner city, the underclass and public policy. Chicago: University of Chicago Press, 1987

7 Wilson WJ. Studying inner-city social dislocations: the challenge of public agenda research. American Sociological Review 1991;56:1-14.

8 Billy JOG, Moore DE. A multilevel analysis of marital and non-marital fertility in the United States. Social Forces 1992;70:977-1011.

9 Brooks-Gunn J, Duncan GJ, Klebanov PK, et al. Do areas affect child and adolescent development? American fournal of Sociology 1993;99:353-95.

10 Crane J. The epidemic theory of ghettos and area effects on dropping out and teenage childbearing. American fournal of Sociology 1991;96:1226-59.

11 South SJ, Crowder KD. Neighborhood effects on family formation: concentrated poverty and beyond. American formation: concentrated poverty a
Sociological Review 1999;64:113-32.

12 Diamond I, Clements S, Stone N, et al. Spatial variation in teenage conceptions in south and west England. Fournal of the Royal Statistical Society A 1999;162;273-89.

13 Evans WN, Oates WE, Schwab RM. Measuring peer group effects: a study of teenage behaviour. Fournal of Political Economy 1992;100:966-91.

14 Manlove J. Early motherhood in an intergenerational perspective: the experience of a British cohort. Fournal of Marriage and the Family 1997;59:263-79.

15 Botting B, Rosato M, Wood R. Teenage mothers and the health of their children. Popul Trends 1998;93:19-28.

16 Dale A. The value of the SARs in spatial and area-level research. Environment and Planning A 1998;30:767-74.

17 Townsend P, Phillimore P, Beattie A. Health and deprivation. London: Routledge, 1989.

18 Goldstein H. Multilevel models in educational and social research. 2nd ed. London: Edward Arnold, 1995.

19 Wright DB. Extra-binomial variation in multilevel logistic models with sparse structures. BrF Math Stat Psychol 1997; 50:21-9.

20 Case A, Katz L. The company you keep: the effects of family and area on disadvantaged youths. NBER W Economic Research, 1991.

21 Coleman JS. Social capital in the creation of human capital. American fournal of Sociology 1988;94:S95-120.

22 Sampson RJ, Raudenbush SW, Earls F. Neighborhoods and violent crime: a multilevel study of collective efficacy. violent crime: a multilevel
Science 1997;277:918-24.

23 Macintyre S, Maciver S, Sooman A. Area, class and health: should we be focusing on places or people. Fournal of Social Policy 1993;22:213-34. 